\title{
POLÍTICAS DE RECONHECIMENTO E IDENTIDADE A PARTIR DE CHARLES TAYLOR E NANCY FRASER
}

\author{
Nélio Lustosa Santos Júnior ${ }^{1}$
}

\begin{abstract}
RESUMO
O presente artigo tem como objetivo articular um diálogo entre as propostas de Charles Taylor e Nancy Fraser acerca das políticas de reconhecimento e identidade. Nesta tarefa, apresentamos a ligação fundamental que Charles Taylor estabelece entre identidade e reconhecimento, a partir de uma dimensão dialógica que privilegia o contato significativo com os outros. Posteriormente, discutimos a concepção de um modelo de status como alternativa ao modelo de identidade na proposta de Nancy Fraser, que compreende o reconhecimento como uma questão de justiça desvinculada de avaliações éticas. Por fim, são contrastadas as concepções de reconhecimento de ambos os pensadores em relação à centralidade da identidade e autorrealização nas políticas de reconhecimento, destacando como as críticas de Fraser a Taylor desconsideram a dimensão intersubjetiva da concepção de identidade do filósofo canadense.
\end{abstract}

PALAVRAS-CHAVE: Modelo de Identidade. Modelo de Status. Paridade Participativa. Políticas de Reconhecimento.

\begin{abstract}
This paper aims to articulate a dialogue between the proposals of Charles Taylor and Nancy Fraser on the politics of recognition and identity. In this task, we present the fundamental connection that Charles Taylor establishes between identity and recognition, from a dialogic dimension that privileges meaningful contact with others. Subsequently, we discussed the conception of a status model as an alternative to the identity model in Nancy Fraser's proposal, which comprises recognition as a matter of justice unrelated to ethical issues. Finally, the conceptions of recognition of both thinkers in relation to the centrality of identity and self-realization in the politics of recognition are confronted, evidencing how Fraser's criticisms of Taylor disregard the intersubjective dimension of the Canadian philosopher's conception of identity.
\end{abstract}

KEYWORDS: Identity Model. Status Model. Participatory Parity. Politics of Recognition.

\section{Introdução}

$\mathrm{Na}$ contemporaneidade, o reconhecimento é uma das categorias centrais para a compreensão das injustiças sociais. Tal destaque é fruto de uma reconstrução filosófica dessa categoria a partir dos escritos do jovem Hegel no período de Jena, cujo destaque se encontra em uma teoria da intersubjetividade desenvolvida em Luta por Reconhecimento (2003), de Axel Honneth. Outro autor que retoma a discussão hegeliana do reconhecimento

\footnotetext{
${ }^{1}$ Mestrando em Filosofia pela Universidade Federal do Piauí (UFPI). E-mail: juniorvilks@gmail.com Perspectivas - Revista do Programa de Pós-Graduação em Filosofia da UFT - n. 1 - 2019
} 
é o filósofo canadense Charles Taylor, em um dos seus textos essenciais, que é A Política do Reconhecimento (2000), no qual ele toma como pano de fundo a luta dos canadenses aborígenes de fala francesa para manter viva sua tradição diante do restante da população de origem anglo-saxã. Além disso, discute as implicações do multiculturalismo para as políticas de reconhecimento, sobretudo aquelas que dizem respeito aos currículos educacionais multiculturalistas.

A discussão sobre o reconhecimento possui também desdobramentos na concepção de justiça da filósofa estadunidense Nancy Fraser. Contudo, ao contrário de pensadores como Charles Taylor e Axel Honneth, ela compreende que as lutas sociais devem levar em conta tanto a dimensão do reconhecimento quanto a redistribuição (FRASER, 2006). ${ }^{2} \mathrm{O}$ reconhecimento, em sua interpretação, prioriza essencialmente os aspectos de injustiça cultural, negligenciando as desigualdades estruturadas na economia.

Uma das obras fundamentais para a compreensão das implicações dessa controvérsia redistribuição-reconhecimento tem como intérpretes Axel Honneth e Nancy Fraser, em Redistribution or recognition? A political-philosophical exchange (2003). Devido ao proveitoso debate de ambos, as suas respectivas propostas são frequentemente colocadas em disputa na filosofia política contemporânea.

Por outro lado, articulações entre as perspectivas de Taylor e Fraser são menos frequentes, apesar da autora encaminhar críticas constantes à política do reconhecimento do filósofo canadense. Nessa direção, o objetivo deste artigo é fornecer um panorama da discussão sobre políticas de reconhecimento e identidade a partir de Charles Taylor e Nancy Fraser, especialmente pelo contraste de suas concepções.

Neste percurso, inicialmente será discutida a análise de Charles Taylor acerca da constituição do Self na modernidade e suas implicações para as noções de reconhecimento e identidade. Posteriormente, são apresentadas as críticas de Nancy Fraser ao modelo de identidade, e uma proposta alternativa de reconhecimento vinculada a um modelo de status. Por fim, são feitas confrontações entre o pensamento desses filósofos no que tange às políticas de reconhecimento e identidade.

\section{Reconhecimento e Identidade na Concepção de Charles Taylor}

\footnotetext{
${ }^{2}$ De modo a fornecer uma teoria de justiça mais adequada às questões colocadas pela globalização e ao enfraquecimento da configuração Keynesiana-Westfaliana, Nancy Fraser acrescentou posteriormente a "representação" como uma terceira dimensão de justiça. Para um aprofundamento dessa ampliação, ver Fraser (2008).

Perspectivas - Revista do Programa de Pós-Graduação em Filosofia da UFT - n. 1 - 2019
} 
Em As fontes do self (1997), Charles Taylor desenvolve um estudo acerca do processo histórico de constituição da identidade moderna, utilizando estratégias da fenomenologia e da hermenêutica. Em seu diagnóstico, a modernidade permitiu o desenvolvimento de um sujeito que julga a si mesmo autossuficiente, negligenciando completamente a importância das relações comunitárias para a formação de sua respectiva identidade.

Essa noção de indivíduo atomizado ocasionou demandas de reconhecimento cada vez mais frequentes, posto que “[...] nossa identidade é moldada em parte pelo reconhecimento ou por sua ausência, frequentemente pelo reconhecimento errôneo por parte dos outros [...]" (TAYLOR, 2000, p. 241, grifo do autor). Portanto, conforme sua interpretação, é irrazoável a defesa de que o indivíduo pode, isolado, definir sua própria identidade.

Segundo Taylor (2000), a preocupação moderna com a identidade e o reconhecimento tem como cerne duas mudanças. A primeira tem a ver com o declínio de hierarquias sociais, sobretudo daquelas marcadas pela noção de honra. Substituindo a concepção de honra, temos a noção moderna de dignidade. A diferença fundamental entre as duas é que a primeira exige intrinsecamente desigualdade, uma vez que é essencial que nem todos tenham honra para ela ter sentido; enquanto a dignidade é compartilhada de forma igualitária e universal por todos os seres humanos.

A segunda mudança apontada pelo autor é o ideal de autenticidade, no qual cada pessoa, na sua condição individualizada, descobre sua identidade em si mesmo. Em outros termos, trata-se do desenvolvimento da autoconsciência. Assim sendo, "não só devo moldar minha vida de acordo com as exigências da conformidade externa como sequer posso encontrar fora de mim o modelo pelo qual viver. Só o posso encontrar dentro de mim" (TAYLOR, 2000, p. 245).

Tal concepção da filosofia moderna, na defesa de Taylor, ignora o aspecto fundamental da condição humana, que é a sua dimensão dialógica. Como exemplo, temos a linguagem, que somente é possível no sentido mais amplo em contato com os outros, uma vez que "as pessoas não adquirem as linguagens de que precisam para se autodefinirem por si mesmas" (TAYLOR, 2000, p. 246).

É nessa direção que ele se apropria da expressão “outros significativos”, cunhada por G. H. Mead, para se referir ao papel fundamental do diálogo e da linguagem nas relações 
humanas, bem como criticar uma determinada visão monológica da vida que subestima o dialógico. Sobre esse ideal monológico, o filósofo afirma:

\begin{abstract}
Ele esquece que nossa compreensão das boas coisas da vida pode ser transformada por nossa fruição delas em comum com pessoas a quem amamos, que alguns bens só se tornam acessíveis a nós mediante essa fruição comum. Por causa disso, seria necessário um imenso esforço, e provavelmente muitas rupturas terríveis, para evitar que nossa identidade seja formada pelas pessoas a quem amamos (TAYLOR, 2000, p. 247, grifo do autor).
\end{abstract}

Nesse sentido, o debate sobre o reconhecimento tornou-se indispensável para a compreensão do isolamento do indivíduo nas sociedades modernas. O desdobramento desses discursos, na concepção tayloriana, aparece frequentemente na esfera íntima, onde ocorre a formação dialógica e conflituosa do Self, e na esfera pública, na qual a política de reconhecimento aparece frequentemente. As duas se relacionam diretamente, na medida em que:

\begin{abstract}
A importância do reconhecimento é agora universalmente reconhecida de uma forma ou de outra; em um plano pessoal, estamos todos cientes de como a identidade pode ser formada ou malformada em nosso contato com outros significantes. No plano social, temos uma contínua política de reconhecimento igualitário. Ambos foram moldados pelo crescente ideal da autenticidade, e o reconhecimento desempenha um papel essencial na cultura que surgiu ao redor dela (TAYLOR, 2011, p. 57).
\end{abstract}

O não reconhecimento ou reconhecimento errôneo, destarte, é uma barreira capaz de afetar diretamente a formação da identidade individual como também de toda uma comunidade. Ao infringir esse aspecto, segundo Taylor, ocorrem opressões das mais variadas, desde a evidência do desrespeito com os outros ao aprisionamento da identidade, o que ocasiona uma autoimagem negativa daqueles que são violados. Por conta disso, o reconhecimento jamais pode ser entendido como uma cortesia, mas como uma exigência constitutiva da humanidade que vai muito além da dimensão do desrespeito (TAYLOR, 2000).

A política de reconhecimento, na esfera pública, teve dois movimentos distintos. $\mathrm{O}$ primeiro relaciona-se com uma política do universalismo, que tende a tratar todos de igual maneira, sem distinções entre cidadãos, enquanto o segundo é pautado pela política da diferença, na qual as pessoas devem ter suas identidades peculiares reconhecidas (TAYLOR, 2000). No âmbito da disputa, existe uma tensão interna que envolve a maneira como ambas as políticas de reconhecimento tratam a questão da diferença.

Perspectivas - Revista do Programa de Pós-Graduação em Filosofia da UFT - n. 1 - 2019 
Em relação ao princípio de universalidade, Taylor destaca afinidades em ambas as políticas, uma vez que, até mesmo os defensores da política da diferença reconhecem o potencial universal presente igualmente em todos. Nesse sentido, é que “[...] só damos o devido reconhecimento àquilo que está universalmente presente - todos têm uma identidade - por meio do reconhecimento do que há de peculiar a cada um" (TAYLOR, 2000, p. 251).

Contudo, semelhante defesa acarreta problemas para os defensores da política da dignidade, para os quais o afastamento do princípio da universalidade prejudica, cada vez mais, a possibilidade de reconhecer aquilo que é comum a todos. Como mediação possível, proponentes dessa perspectiva recorrem ao próprio conceito de dignidade para justificar a inclusão de minorias em suas políticas, a partir de medidas de discriminação reversa “[...] como medida temporária que eventualmente equilibrará os pratos da balança e permitirá que as antigas regras "cegas" voltem a vigorar de uma maneira que não ponha ninguém em desvantagem" (TAYLOR, 2000, p. 252), tal como cotas raciais. No entanto, na concepção de Taylor, a discriminação reversa não consegue responder adequadamente questões que exigem reconhecimento a partir das diferenças.

Ademais, os proponentes radicais da política da diferença reclamam constantemente o problema da distintividade do liberalismo pautado na visão restritiva dos direitos iguais, marcado pelo seu caráter homogeneizante. Como forma de afastar essa crítica, Taylor sugere uma concepção de liberalismo não procedimental aberto às diferenças. Isso porque, em sua visão, um liberalismo que “[...] (a) insiste na aplicação uniforme das regras que definem esses direitos [de igual respeito], sem exceção, e (b) suspeita de metas coletivas" (TAYLOR, 2000, p. 265) é incapaz de garantir a sobrevivência de uma comunidade.

Nesse cenário, “[...] ele defende a possibilidade de que, dentro de uma visão liberal, seja possível uma outra interpretação, que estabeleça uma outra relação entre aplicação uniforme da norma e respeito a metas coletivas, e não seja tão homogeneizante" (SAAVEDRA e SOBOTTKA, 2009, p. 390). Tal leitura do liberalismo, portanto, representa uma tentativa de responder as principais objeções levantadas pelos políticos da diferença no tocante ao liberalismo, oferecendo pressupostos compatíveis com sociedades multiculturais. ${ }^{3}$

\footnotetext{
${ }^{3}$ Para uma crítica dessa leitura tayloriana, Cf. HABERMAS, Jürgen. A luta por reconhecimento no Estado democrático de direito. In: ___ . A inclusão do outro, p. 229-267, 2002.

Perspectivas - Revista do Programa de Pós-Graduação em Filosofia da UFT - n. 1 - 2019
} 


\section{Reestruturação do Reconhecimento em Nancy Fraser}

$\mathrm{Na}$ teoria de justiça de Nancy Fraser, o reconhecimento aparece como uma das categorias emergentes naquilo que ela chama de "era pós-socialista" (FRASER, 2006). As "lutas por reconhecimento", por conseguinte, tornaram-se os conflitos políticos centrais dos movimentos sociais contemporâneos. Fraser confirma a legitimidade dessas demandas, no entanto, está preocupada com a simples substituição das reivindicações de redistribuição pelas de reconhecimento.

Em seu diagnóstico, a dimensão cultural passou a ser vista como a fonte preeminente de injustiças em um mundo que é também marcado por profunda desigualdade material. Por essa razão, sua proposta busca integrar reconhecimento e redistribuição em uma ampla teoria de justiça capaz de enfrentar tanto as injustiças culturais como as injustiças econômicas. Para tanto:

Isso significa, em parte, pensar em como conceituar reconhecimento cultural e igualdade social de forma a que sustentem um ao outro, ao invés de se aniquilarem (pois há muitas concepções concorrentes de ambos!) Significa também teorizar a respeito dos meios pelos quais a privação econômica e o desrespeito cultural se entrelaçam e sustentam simultaneamente. Exige também, portanto, esclarecer os dilemas políticos que surgem quando tentamos combater as duas injustiças ao mesmo tempo (FRASER, 2006, p. 231).

Outra tarefa consiste em desafiar a polarização em que se encontram as duas categorias no âmbito da filosofia moral. De um lado, o reconhecimento tem uma vinculação forte com a Sittlichkeit (ética) hegeliana, já a redistribuição vincula-se com a Moralität (moralidade) kantiana. Logo, "Nesses alinhamentos usuais, os dois lados concordam que a distribuição pertence à moralidade, o reconhecimento pertence à ética, e ambos nunca se encontrarão. Então, cada um sustenta que o seu paradigma exclui o do outro" (FRASER, 2007, p. 105).

As tentativas de desvinculação ou questionamento desses alinhamentos rígidos, conforme a autora, correm o risco de parecer "esquizofrenia filosófica" (FRASER, 2007). Inicialmente, ela concorda que a redistribuição pertença ao campo da moralidade, no entanto, defende a possibilidade de construção de uma política do reconhecimento desvinculada da ética, compreendendo o reconhecimento não como uma questão de "boa vida", mas como uma reivindicação de justiça. Teoricamente, isso requer que Fraser se afaste das políticas de

Perspectivas - Revista do Programa de Pós-Graduação em Filosofia da UFT - n. 1 - 2019 
reconhecimento ligadas ao modelo de identidade, que ela julga problemático em dois aspectos centrais (FRASER, 2010).

No primeiro deles, denominado "problema de deslocamento", as lutas por reconhecimento tratam as injustiças como oriundas exclusivamente da cultura; inclusive, mesmo quando reconhecem a má redistribuição (maldistribution) como obstáculo para o alcance de justiça social, defendem que, ao resolver os obstáculos do não reconhecimento (misrecognition), os problemas da má redistribuição são igualmente resolvidos. Nessa visão culturalista, a questão distributiva é dissolvida da gramática de justiça, recaindo em uma concepção monista incapaz de responder adequadamente aos problemas que estão para além da dimensão cultural.

No segundo aspecto, denominado "problema de reificação", grupos sociais pautados no modelo identitário tendem a construir imagens essencializadas e homogêneas de seus próprios integrantes, além de negar as diferenças e lutas internas aos próprios movimentos sociais. Alinhada com essa concepção está a presunção de que as culturas são fixas e isoladas, como se as diferenças culturais não tivessem continuidades e descontinuidades.

Outro problema subjacente ao modelo de identidade deriva da compreensão de que o não reconhecimento resulta necessariamente em uma subjetividade ou autoidentidade danificada, como na concepção de Charles Taylor. Segundo a autora, "Quando o não reconhecimento é identificado com distorções internas na estrutura da autoconsciência do oprimido, basta apenas um pequeno passo para culpar a vítima" (FRASER, 2007, p. 113). Evidentemente, ela assume que o não reconhecimento pode ter efeitos psicológicos naquele que são vítimas; no entanto, o reconhecimento independe da presença desses efeitos psíquicos ou da percepção dos sujeitos em relação a essas sequelas.

Isso significa que as experiências patológicas vividas pelos sujeitos podem ser inapreensíveis para eles mesmos. Não seria problemático em termos teóricos fazer com que categorias críticas e normativas derivassem do sentimento de desrespeito vivido subjetivamente pelos afetados? [...] Certamente poderíamos continuar diante de interações distorcidas, pois as expectativas do reconhecimento estão atreladas a comportamentos socialmente construídos, isto é, a relações de poder. Portanto, quanto ao problema da motivação moral da luta, o sentimento de desrespeito não implicaria a presença real de uma assimetria de reconhecimento (MELO, 2014, p. 28).

A solução para tais problemas, em contrapartida, consiste em compreender o reconhecimento inserido na perspectiva de um modelo de status, apoiado na acepção weberiana. Nessa proposta, “[...] o que exige reconhecimento não é a identidade específica 
de um grupo, mas a condição dos membros do grupo como parceiros integrais na interação social" (FRASER, 2007, p. 107). Ao invés da auto-afirmação da identidade específica de um grupo, o foco das políticas de reconhecimento deve ser o enfrentamento dos obstáculos que impedem as pessoas de participar como iguais na vida social. Em outras palavras:

\begin{abstract}
Entender o reconhecimento como uma questão de status significa examinar os padrões institucionalizados de valoração cultural em função de seus efeitos sobre a posição relativa dos atores sociais. Se e quando tais padrões constituem os atores como parceiros, capazes de participar como iguais, com os outros membros, na vida social, aí nós podemos falar de reconhecimento recíproco e igualdade de status. Quando, ao contrário, os padrões institucionalizados de valoração cultural constituem alguns atores como inferiores, excluídos, completamente "os outros" ou simplesmente invisíveis, ou seja, como menos do que parceiros integrais na interação social, então nós podemos falar de não reconhecimento e subordinação de status (FRASER, 2007, p. 108, grifos da autora).
\end{abstract}

A proibição do casamento homossexual e práticas de policiamento baseadas em “categorização racial” são alguns dos exemplos citados por Fraser (2007) para mostrar como padrões institucionalizados promovem subordinação de status. Enquanto o casamento heterossexual é institucionalizado e tido como "normal", os casais homossexuais são "perversos". Pessoas brancas são tidas como "obedientes à lei”, enquanto negros são "potencialmente criminosos". As instituições, aos reforçarem padrões de valoração cultural como aceitáveis e outros como inaceitáveis acabam legitimando injustiças.

No modelo de status, em alternativa, as demandas de reconhecimento buscam promover os sujeitos como pares integrais da vida social. Tem como objetivo, portanto, desinstitucionalizar padrões de valoração cultural que excluam sujeitos e grupos, colocando em seu lugar padrões que promovam o princípio da "paridade de participação", sustentando que "A justiça requer arranjos sociais que permitam a todos os membros (adultos) da sociedade interagir entre si como pares" (FRASER, 2002, p. 13).

Conforme Fraser (2010), nessa concepção de reconhecimento em termos de status, os impedimentos institucionais à paridade de participação não estão limitados somente aos padrões de valoração cultural. A própria redistribuição injusta dos recursos materiais figura como obstáculo à efetivação da paridade, uma vez que o modelo de status pretende abranger também a subordinação social assentada na estrutura econômica da sociedade, tendo em vista que "[...] as injustiças são produzidas por fatores intercruzados, e daí a dificuldade em dirimi-los já que as estratégias comumente focam apenas em um fator em detrimento de 
outro perdendo, desta forma, a noção de conjunto no enfrentamento de injustiças (LIMA, 2016, p. 135).

Como não essencializa as identidades, o modelo de status é capaz de enfrentar a homogeneização e dominação interna aos grupos sociais, bem como evitar a subordinação social. Consequentemente, o reconhecimento é entendido como uma reivindicação de justiça a ser enfrentada pelo princípio da paridade participativa. Portanto, está mais próximo de uma abordagem deontológica que não se vincula apressadamente ao campo da ética. Isso permite, teoricamente, que Nancy Fraser consiga percorrer rumo à conciliação das categorias do reconhecimento e redistribuição.

\section{Contraste do Debate Taylor-Fraser acerca das Políticas de Reconhecimento}

O debate sobre redistribuição-reconhecimento tem como um dos marcos significativos, como dissemos anteriormente, o confronto estabelecido entre Nancy Fraser e Axel Honneth na obra Redistribution or recognition? (2003), na qual ambos expõem seus argumentos favoráveis a uma teoria de justiça unidimensional (Honneth) ou bidimensional (Fraser).

Apesar das divergências teóricas entre Axel Honneth e Charles Taylor em referência ao reconhecimento, os dois partem de pressupostos similares em relação ao tema, reinterpretando bases do reconhecimento hegeliano. Isso permite que boa parte dos questionamentos de Fraser direcionados a Honneth sejam encaminhados a Charles Taylor, o que a filósofa já faz em alguns de seus escritos.

Uma divergência central entre o pensamento de Fraser e Taylor reside no papel que a identidade ocupa nas políticas de reconhecimento. Como vimos anteriormente, para Taylor, a identidade representa um dos aspectos indispensáveis da nossa constituição humana. Como nossa identidade é elaborada, em parte, a partir do reconhecimento, "O nãoreconhecimento ou o reconhecimento errôneo podem causar danos, podem ser uma forma de opressão, aprisionando alguém numa modalidade de ser falsa, distorcida e redutora" (TAYLOR, 2000, p. 241).

A respeito da afirmação acima, Fraser destaca que tanto Honneth quanto Taylor “[...] entendem o não reconhecimento em termos de uma subjetividade prejudicada e uma autoidentidade danificada. E ambos entendem a lesão em termos éticos, como um impedimento à capacidade do sujeito de alcançar a boa vida" (FRASER, 2007, p. 111). De encontro a tal 
interpretação, a autora compreende o reconhecimento como uma exigência de justiça. Teoricamente, ela defende que:

\begin{abstract}
Desse modo, não se deve responder à pergunta "O que há de errado com o falso reconhecimento?" [...] Deve-se dizer, ao contrário, que é injusto que, a alguns indivíduos e grupos, seja negada a condição de parceiros integrais na interação social, simplesmente em virtude de padrões institucionalizados de valoração cultural, de cujas construções eles não participaram em condições de igualdade, e os quais depreciam as suas características distintivas ou as características distintivas que lhes são atribuídas (FRASER, 2007, p. 112).
\end{abstract}

Entre as vantagens dessa abordagem, Fraser destaca a possibilidade de reivindicar reconhecimento sob os termos de um pluralismo valorativo, visto que na modernidade, não é razoável acreditar que existe uma concepção de boa vida que possa ser universalmente compartilhada. Além do mais, "Concebendo o não reconhecimento como subordinação de status, ele localiza o equívoco nas relações sociais, e não na psicologia individual ou interpessoal" (FRASER, 2007, p. 113).

Vale ressaltar que Taylor atribui um caráter fundamental para o dialógico na formação da identidade, "Assim sendo, minha descoberta de minha identidade não implica uma produção de minha própria identidade no isolamento; significa que eu a negocio por meio do diálogo, parte aberto, parte interno, com o outro" (TAYLOR, 2000, p. 248). Posto assim, a crítica de Fraser parece não atingir a noção de identidade tayloriana, tanto é que ele reconhece a impossibilidade de formação de uma identidade apartada da dimensão social.

A própria distinção das modalidades de política de reconhecimento colocada pelo filósofo canadense esclarece tanto sua proposta, como a crítica de Nancy Fraser. Quando a filósofa propõe repensar o reconhecimento, a maior parte de suas objeções está centrada nos problemas suscitados pela interpretação do modelo identitário de reconhecimento, chamado por Taylor de política da diferença, na qual:

Todos devem ter reconhecida sua identidade peculiar. Mas reconhecimento significa algo mais. Com a política da dignidade igual, aquilo que é estabelecido pretende ser universalmente o mesmo, uma cesta idêntica de direitos e imunidades; com a política da diferença, pedem-nos para reconhecer a identidade peculiar desse individuo ou grupo, aquilo que o distingue de todas as outras pessoas (TAYLOR, 2000, p. 250).

Partindo de uma interpretação pragmatista, Fraser entende que, em algumas situações, será necessário o reconhecimento da especificidade de um grupo com objetivo de combater injustiças. Por tal razão, ela reconhece que o combate da subordinação de gênero,

Perspectivas - Revista do Programa de Pós-Graduação em Filosofia da UFT - n. 1 - 2019 
por exemplo, deve levar em conta a capacidade distintiva das mulheres gerarem filhos. Para Fraser (20007, p. 123), "Então, não podemos descartar apressadamente a possibilidade de que a justiça pode requerer o reconhecimento das particularidades em alguns casos”.

Uma segunda discordância a ser destacada é a necessidade de autorrealização como requisito para a formação de uma identidade não distorcida. Enquanto "Taylor $(1997,1994)$ está essencialmente preocupado com os processos de construção do self, defendendo que os indivíduos dependem do reconhecimento intersubjetivo para se auto-realizarem" (MENDONÇA. 2009, p. 144), Fraser compreende tal paradigma como problemático em diversos aspectos, defendendo como alternativa o princípio normativo da "paridade de participação".

Fraser insiste que o reconhecimento deve desprender-se de um modelo pautado pela autorrealização, que ela julga psicologizante. Ao invés de justificar as reivindicações por reconhecimento em termos de efeitos psicológicos, “[...] o não reconhecimento é uma questão de impedimentos, externamente manifestados e publicamente verificáveis, a que certos indivíduos sejam membros integrais da sociedade" (FRASER, 2000, p. 114). Segundo a autora, dentre outras vantagens, isso permite diferenciar as lutas por reconhecimento

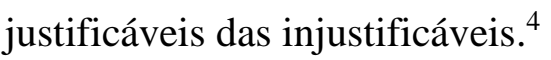

De acordo com Mendonça (2009), a acusação de Fraser ignora a dimensão intersubjetiva da política de reconhecimento tayloriana. Como decorrência, "Se a autorealização é uma contínua construção dialógica, ela não pode ser entendida nem como imposta de fora nem como a mera expressão de desejos individuais" (MENDONÇA, 2009, p. 149). Desse modo, Taylor não concebe as identidades como pré-moldadas; ao contrário, elas são formadas em conflito e diálogo constante. Ou seja, a autorrealização está intrinsecamente ligada ao contato com o outro, logo, demandas de reconhecimento que excluem o "outros significativos", tais como posturas racistas, estão fora de questão.

Em relação ao âmbito da filosofia moral, as divergências entre os dois pensadores são mais acentuadas. Nancy Fraser, de um lado, é contrária às políticas de reconhecimento em termos de "bem" e "boa vida". Isto significa, em parte, que o reconhecimento deve se afastar, o máximo possível, de avaliações éticas. Taylor, por sua vez, defende uma visão de

\footnotetext{
${ }^{4}$ Para Fraser (2007), as lutas por reconhecimento fundamentadas com base na autorrealização correm o risco de respaldar posturas extremistas e preconceituosas. Como considerar injustificáveis, por exemplo, as reivindicações de reconhecimento de identidades racistas, se a autoestima e autorrealização desses sujeitos é sustentada pela categorização de outras pessoas como inferiores?

Perspectivas - Revista do Programa de Pós-Graduação em Filosofia da UFT - n. 1 - 2019
} 
"boa vida" como fonte para a formação do Self, vinculada à comunidade em que os membros são formados.

Em seu diagnóstico da modernidade, à luz de Hegel, Taylor (2005) preocupa-se centralmente com o individualismo, no qual o sujeito deixa de se identificar com a vida em comunidade, buscando em si mesmo os elementos para formação de sua identidade. Contrário a tal visão, Taylor defende que, "Nesse sentido, nós só somos o que somos como seres humanos dentro de uma comunidade cultural. Talvez, uma vez que tenhamos nos desenvolvido plenamente numa cultura, possamos deixa-la e ainda assim reter muito dela" (TAYLOR, 2005, p. 113).

Nancy Fraser, de outro modo, recusa com veemência a defesa de políticas de reconhecimento sustentadas por padrões teleológicos. De forma peremptória, ela afirma que:

[...] qualquer tentativa de justificar reivindicações por reconhecimento que apele para uma concepção da boa vida será necessariamente sectária. Nenhuma abordagem desse tipo pode entender tais reivindicações como normativamente vinculantes para aqueles que não compartilham do horizonte de valores éticos do teórico (FRASER, 2007, p. 112).

Diversamente, deve-se propor um modelo deontológico - nesse caso, o modelo de status - capaz de dar vazão à "liberdade subjetiva", no qual cada indivíduo decide, para si próprio, o que deve ser priorizado como vida boa (FRASER, 2007). Ao postular a liberdade subjetiva, Fraser parece evocar justamente aquilo que Charles Taylor evita em sua obra; no caso, a ideia de que o sujeito pode definir, por si só, aquilo que é essencial para a formação de sua identidade.

\section{Conclusão}

O presente artigo buscou formular um panorama do debate entre Nancy Fraser e Charles Taylor sobre políticas de reconhecimento e identidade. Para tanto, fez-se necessário apresentar como a questão da identidade e reconhecimento perpassa a obra tayloriana. Posteriormente, foi apresentado o trajeto teórico que Fraser utiliza para defender o reconhecimento em termos deontológicos, substituindo o modelo de identidade pelo modelo de status, com objetivo de desvincular o reconhecimento, pelo menos inicialmente, de avaliações éticas. Por último, foram discutidas as divergências entre o pensamento dos autores.

Perspectivas - Revista do Programa de Pós-Graduação em Filosofia da UFT - n. 1 - 2019 
A preocupação com o reconhecimento e a identidade, como vimos, aparece na obra de Taylor frequentemente como uma emergência da sociedade moderna, cujo indivíduo se percebe isolado de um contexto mais amplo, desvinculado da vida em comunidade. Nesse sentido, ele destaca a importância dos valores e práticas culturais de uma determinada comunidade, que fornecem aos indivíduos um horizonte ético amplo para suas vidas.

Fraser, por sua vez, percebe que as políticas de reconhecimento vinculadas à noção de bem levam ao sectarismo. Além disso, defende o reconhecimento em termos deontológicos, alinhado com as políticas de redistribuição. Em tal aspecto, Fraser afirma que Charles Taylor, bem como Honneth, negligenciam em suas discussões a questão redistributiva, reduzindo as injustiças sociais ao âmbito do reconhecimento. Logo, um dos méritos de sua teoria de justiça é fornecer uma alternativa à polarização em que se encontram os defensores do reconhecimento e da redistribuição.

Ao que tudo indica, a nosso ver, as principais críticas de Nancy Fraser não afetam os argumentos da teoria de Charles Taylor. De modo semelhante à Mendonça (2009), partilhamos da ideia que a filósofa americana não levou em conta a intersubjetividade presente na abordagem de Taylor, tampouco o tipo de comunitarismo que ele defende, afinal, “[...] a defesa da noção gadameriana de fusões de horizontes evidencia o cuidado de Taylor de evitar a proposição de um comunitarismo sectário" (MENDONÇA, 2009, p. 149).

Esse julgamento, todavia, apresenta um problema crucial. Infelizmente, ao contrário do paralelo Fraser-Honneth acerca da redistribuição-reconhecimento, cujos entendimentos estão centralizados em uma obra, as tentativas de diálogo entre as percepções de Taylor e Fraser em torno do reconhecimento são menos comuns. O próprio filósofo canadense, salvo engano, sequer cita os argumentos de Nancy Fraser contra sua teoria. Ela, pelo contrário, discute a proposta de Taylor em diversos momentos, colocando o autor como um dos maiores expoentes da teoria do reconhecimento. Provavelmente, um debate direto tornaria mais claro as fragilidades da teoria de ambos, de tal modo que o reconhecimento, assim como concebido por cada um deles, dificilmente sairia intacto. 


\section{REFERÊNCIAS BIBLIOGRÁFICAS}

FRASER, Nancy. A justiça social na globalização: Redistribuição, reconhecimento e participação. Revista Crítica de Ciências Sociais, Portugal, n. 63, p. 07-20, 2002.

Disponível em: <journals.openedition.org/rccs/pdf/1250>. Acesso em: 18 set. 2018.

. Da redistribuição ao reconhecimento? Dilemas da justiça numa era "pós-socialista".

Cadernos de Campo, São Paulo, v. 15, n. 14-15, p. 231-239, 2006. Disponível em: <revistas.usp.br/cadernosdecampo/article/download/50109/54229>. Acesso em: 18 set. 2018.

Reconhecimento sem ética? Lua Nova, São Paulo, v. 70, n. 1, p. 101-138, 2007. Disponível em: <scielo.br/pdf/ln/n70/a06n70.pdf>. Acesso em: 18 set. 2018.

. Repensando o reconhecimento. Enfoques, Rio de Janeiro, v. 9, n. 1, p. 114-128, 2010. Disponível em:<enfoques.ifcs.ufrj.br/ojs/index.php/enfoques/article/view/102/94>. Acesso em: 18 set. 2018.

; HONNETH, Axel. Redistribution or recognition? A political-philosophical exchange. Translated by Joel Golb, James Ingram, and Christiane Wilke. New York: Verso, 2003.

Scales of Justice: Reimagining political space in a globalizing world. New York: Columbia University Press, 2010.

HABERMAS, Jürgen. A luta por reconhecimento no Estado democrático de direito. In: A inclusão do outro, p. 229-267, 2002.

LIMA, Francisco Jozivan Guedes de. Para além do dilema redistribuição-reconhecimento: Nancy Fraser e a concepção bidimensional de justiça. ethic@ - An international Journal for Moral Philosophy, Santa Catarina, v. 15, n. 1, p. 126-141, 2016. Disponível em:<periodicos.ufsc.br/index.php/ethic/article/view/1677-2954.2016v15n1p126/32308>.

Acesso em: 10 set. 2018.

MELO, Rúrion. Da teoria à práxis? Axel Honneth e as lutas por reconhecimento na teoria política contemporânea. Revista Brasileira de Ciência Política, Brasília, n. 15, p. 17-36, 2014. Disponível em:<scielo.br/pdf/rbcpol/n15/0103-3352-rbcpol-15-00017.pdf >. Acesso em: 10 set. 2018.

MENDONÇA, Ricardo Fabrino. Dimensão intersubjetiva da auto-realização: em defesa da teoria do reconhecimento. Revista Brasileira de Ciências Sociais, São Paulo, v. 24, n. 70, p. 143-154, 2009. Disponível em:<scielo.br/pdf/rbcsoc/v24n70/a09v2470.pdf>. Acesso em: 10 set. 2018.

SAAVEDRA, Giovani Agostini; SOBOTTKA, Emil Albert. Discursos filosóficos do reconhecimento. Civitas, Porto Alegre, v. 9, n. 3, p. 386-401, 2009. Disponível em: $<$ revistaseletronicas.pucrs.br/ojs/index.php/civitas/article/view/6898/6805>. Acesso em: 10 set. 2018.

TAYLOR, Charles. A Ética da Autenticidade. São Paulo: Realizações Editora, 2011.

A política do reconhecimento. In: TAYLOR; Charles. Argumentos filosóficos. São Paulo: Edições Loyola, 2000. p. 241-274.

Perspectivas - Revista do Programa de Pós-Graduação em Filosofia da UFT - n. 1 - 2019 

1997.

As fontes do self: a construção da identidade moderna. São Paulo: Edições Loyola, Hegel e a Sociedade Moderna. São Paulo: Edições Loyola, 2005. 